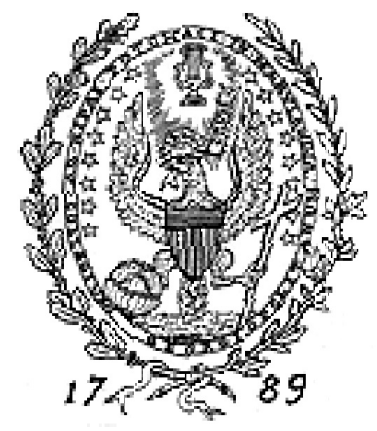

Bioethics Research Library

The Joseph and Rose Kennedy Institute of Ethics

Box 571212, Georgetown University

Washington, DC 20057-1212

202-687-3885; fax: 202-687-8089

bioethics@georgetown.edu

http://bioethics.georgetown.edu

\title{
Public Health Ethics: \\ Health by the Numbers
}

\author{
Martina Darragh \\ Pat Milmoe McCarrick \\ Revised October, 1998
}

Hippocrates had nothing to say about public health. Rather, the idea that a government should protect its citizens from disease by maintaining sanitary conditions has its origin in Renaissance humanities texts, and the notion that physicians have public health responsibilities emerged in the works of such Enlightenment authors as Johann Peter Frank, Benjamin Rush, and John Gregory (II, Coughlin and Beauchamp 1996). When the spread of infectious diseases such as typhoid and cholera accompanied the growth of the Industrial Revolution, England was the first to respond by passing the Public Health Act of 1848. The motivation for this reform was not based in humanitarian concerns but in the realization that unsanitary conditions were costly to industry. "... [The] founders of the public movement were guided by nineteenth century utilitarian moral theories ... the greatest good for the greatest number ... accompanied by a growing appreciation for the innate value and dignity of mankind . . . however, the rights and autonomy of individuals have not always been in pursuing these important objectives" (I, Coughlin 1995, p. 1).

Public health projects have improved global health status dramatically. One measure of their success is that ". . most poor people now live longer, on average, than the wealthiest people a century ago" (I, Beaglehole and Bonita 1997, p. 13). These projects are not limited to such activities as disinfecting sewers. "Public health is what we, as a society, do to collectively assure the conditions in which people can be healthy.

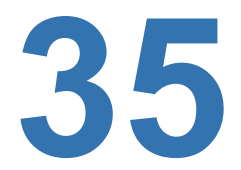


This requires that continuing and emerging threats to the health of the public be successfully countered. These threats include immediate crises, such as the AIDS epidemic; enduring problems, such as injuries and chronic illness; and impending crises foreshadowed by such developments as the toxic byproducts of a modern economy" (I, Institute of Medicine (TOM) 1988, p. 1) The practice of public health has embraced this IOM challenge and includes the subspecialties of epidemiology, health promotion and education, public health administration, international health, maternal and child health, biostatistics, environmental health, and nutrition. This annotated bibliography focuses on epidemiology, health promotion and education, and public health administration, and includes a wide variety of opinions on each topic.

\section{EPIDEMIOLOGY}

At first glance, it is hard to see what ethical issues could arise in population studies of the causes and control of illness. Disclosure of risk information in the clinical encounter is complicated by issues of uncertainty with regard to the data itself. Causation and causal inference may be affected by "wish bias," leading to studies that use the same data but reach widely varying conclusions (II, Weed 1997). Given the complexity of the statistical calculations used to validate public health recommendations, and mass media's portrayal of them, the public may be unintentionally deceived by population-based recommendations (V, Seedhouse 1997; II, Lupton 1995). With the addition of genetic screening, another layer of statistical complexity is added to this mix (VI, Stone and Steward 1996).

\section{HEALTH PROMOTION AND EDUCATION}

Increased life expectancy brought about by advances in public health has raised a new set of problems. With the realization that illness can be promoted in part by individual life-style choices, population-based recommendations about risk factors become important in the clinical encounter. This shift is not without difficulties; one author notes that he has yet to receive any risk information from his physicians, even when he asks "the experts" (V, Dugdale 1998). This may be due in part to the fact that ". . . public health lacks a vocabulary with which to speak about and identify commonalities among health problems experienced by very different populations" (IV, Mann 1997, p. 8). Furthermore, the mix of disciplines informing health promotion activities (sociology, psychology, recreation medicine, and the like) creates an illusion of shared ethics where none exists, which in turn leads to programs based on value systems that may not be meaningful for the populations they serve (V, Seedhouse 1997).
Given these factors, a number of authors are skeptical of introducing public health measures into the clinical encounter. "We might do well to encourage people to live lives of modified hedonism so that they might enjoy to the full the lives that they are likely to have, rather than to portray life as a journey beset with avoidable dangers" (II, McCormick 1996, p. 620). Conversely, Daniel Callahan argues that since health expenditures cannot rise indefinitely, public health measures must go beyond "education and exhortation ... [c] oercive programs will be necessary" (II, Callahan 1998, p.199).

\section{PUBLIC HEALTH ADMINISTRATION}

Ironically, one reason that public health directives can take on the air of moral imperatives is that we live in a secular age. ". . . [F] ocusing upon one's diet and other lifestyle choices has become an alternative to prayer and righteous living in providing a means of making sense of life and death. 'Healthiness' has replaced 'Godliness' as a yardstick of accomplishment and proper living" (II, Lupton 1995, p. 4). The literature of public health ethics critiques current practices and suggests ways to construct healthy societies without stigmatizing individuals or groups. "Public health ultimately rests on the search for a shared solution to common troubles. But how do we construct such a community? . . . Moral outrage can be turned away from evil individuals and onto larger structures-unjust laws or harsh economic regimes" (II, Morone 1997, p.1016).

The following annotations are arranged alphabetically by author within the following categories:
I. General Literature
II. Philosophical and Ethical Issues
III. Socioeconomic/ Legal Perspectives
IV. Individual versus Societal Rights
V. Risk, the Media, and Personal Choice
VI. Genetics and Public Health.

\section{GENERAL LITERATURE}

Beaglehole, Robert, and Bonita, Ruth. Public Health at the Crossroads: Achievements and Prospects. New York: Cambridge University Press, 1997. 243 p.

The authors caution that tremendous improvements in world health are jeopardized by the marginalization of public health and epidemiology by uncritical allegiance to individualism. The book is divided into three sections: an overview of world health and the burden of disease; the accomplishments and failures of epidemiology; and international models for health care delivery. They write that basic principles of medical ethics (respect for autonomy, nonmaleficence, beneficence, and justice) apply to public health, 
but that "[p]ublic health practitioners, and especially health promoters, will achieve more by focusing on the provision of health enabling conditions and opportunities," especially issues of human rights.

Brandt, Allan M., and Rozin, Paul, eds. Morality and Health. New York: Routledge, 1997. 416 p.

The authors collected essays from the disciplines of psychology, medicine, history, sociology, political science, anthropology, sociology, and the law to "focus on the history of attitudes and values associated with diseases and disease related behaviors such as drinking, smoking, drug use, diet, as well as the social, psychological and cultural perspectives of the ways morality shapes our understanding of who gets sick and why." Noting the "complex relationship of morality to health," the authors in this book think that medicine is not wholly objective, scientific, and definite, but that "medicine and morals are deeply and fundamentally entangled."

Brundtland, Gro Harlem. Reaching Out for World Health. [Editorial.] Science 280(5372): 2027, 26 June 1998.

As Director-General of the World Health Organization (WHO), Brundtland notes that this century has been a time of "more gains in public health than in the entire previous history of humankind." The author predicts that the next century will see an increase in interdisciplinary research to combat new infectious diseases on a global scale. "The very progress of our civilization can threaten our health," she notes, and "[r] esearch networks that span national borders will provide essential support for intensified public health efforts."

Cairns, John. Matters of Life and Death: Perspectives on Public Health, Molecular Biology, Cancer, and the Prospects for the Human Race. Princeton, NJ: Princeton University Press, 1997. 257 p.

Cairns points out that the last two centuries have altered life expectations so that people, even in less-developed nations, expect to grow old in reasonably good health. His essays touch on population growth, the enormous changes created by molecular biology, the epidemiology of cancer, and a history of mortality, particularly life expectancy throughout the world.

Coughlin, Steven S. Ethics in Epidemiology and Clinical Research: Annotated Readings. Chestnut Hill, MA: Epidemiology Resources, 1995. 272 p.

This collection of reprinted essays traces the evolution of ethics and health services research from Walter Reed's yellow fever experiments to the development of international guidelines for population-based research. Each reading is accompanied by a brief commentary. The book covers historical, clinical, and philosophical issues in epidemiological research.

Coughlin, Steven S. Ethics In Epidemiology and Public Health Practice: Collected Works. Columbus, GA: Quill Publications, 1997. 232 p.

This selection of articles by Coughlin and colleagues provides an overview of the ethical issues in public health and epidemiology. They discuss core values and the "dual obligations of public health professionals to acquire and apply scientific knowledge aimed at restoring and protecting the public's health while respecting individual rights to autonomy."

Coughlin, Steven S.; Soskolne, Cohn L.; and Goodman, Kenneth W. Case Studies in Public Health Ethics. Washington, DC: American Public Health Association, 1997. $180 \mathrm{p}$.

This collection covers such topics as moral reasoning, informed consent, and scientific misconduct in public health practice. An instructor's guide is included for use in classroom teaching.

Faden, Ruth R., and Kass, Nancy E. Bioethics and Public Health in the 1980s: Resource Allocation and AIDS. Annual Review of Public Health 12: 335-60, 1991.

After identifying trends in the content of BIOETHICSLINE citations for 1980-1989, the authors review the two key ethical issues in public health for the decade: just allocation of existing health care resources and public health measures for addressing the AIDS epidemic. While noting that the "normative dimensions of several key issues (and areas) in public health remained relatively unexplored," they predict that ". . . the ethical issues for public health in the 1990s will not differ sharply in many respects from those of the 1980s."

Henig, Robin Marantz. The People's Health: A Memoir of Public Health and Its Evolution at Harvard. Washington, DC: Joseph Henry Press, 1997. 244 p.

The author examines the evolution of public health problems beginning with cholera and continuing to AIDS and re-emergent, drug resistant tuberculosis, saying that public health has reshaped thinking about the environment and personal behavior. Henig thinks that public health must "deal with issues that encompass nearly every aspect of our 
lives, including race, ethics, economics, politics, sexual and family behavior, genetic predisposition, social infrastructure, and even a population's belief in its own collective future."

Institute of Medicine, Committee for the Study of the Future of Public Health. The Future of Public Health. Washington, DC: National Academy Press, 1988. $225 \mathrm{p}$.

The Committee defines the mission of public health as the fulfillment of society's interest in maintaining conditions in which people can be healthy; the core functions are assessment, policy development, and assurance. Presenting a thorough study of public health's duties and obligations, the report says that "Americans must be concerned that there are adequate public health services in their communities. ..."

Leeman, Eve. Misuse of Psychiatric Epidemiology. Lancet 351(9116): 1601-2, 30 May 1998.

Leeman discusses discrepancies in two large-scale surveys in psychiatry, the Epidemiologic Catchment Area study (ECA) and the National Comorbidity Study (NCS), and notes that "[s]cientific shortcomings in the predictive value of these surveys are now being raised as reasons for limiting treatment in the managed-care era." The author concludes that "[s]cientists may argue about the best way to further refine psychiatric epidemiology," but that these differences of opinion “. . . should not give policymakers and insurance companies permission to refuse psychiatric care to ill patients. ..."

Nikku, Nina, and Eriksson, Bengt Erik. Preventive Medicine. In Encyclopedia of Applied Ethics, vol. 3, ed. Ruth Chadwick, pp. 643-48. San Diego, CA: Academic Press, 1998.

Describing primary prevention, the authors divide their essay into six sections: the field of preventive medicine, ethical dimensions of preventive medicine, social steering and preventive medicine, target groups of preventive medicine, prevention and entertainment (combining health information with entertainment), and the applied ethics of preventive medicine.

Porter, Dorothy, ed. The History of Public Health and the Modern State. Amsterdam: Rodopi B.V., 1994. $439 \mathrm{p}$.

Pointing out that 40 years ago public health was seemingly "triumphant in achieving massive reductions in mortality," but now "problems of world health seem to be far from resolved," Porter's book "interrogates public health's past... posing new questions, seeking new understanding."
Each of the 12 chapters discusses public health in a different country, touching on eugenics, the expansion of bureaucracy, the medicalization of public health, "medical police," and, in the United States, "how environmental hygiene as evangelical moral reform also underlaid the early public health movement." Porter concludes that public health was not created as a response to disease or to industrialization, but as an expression of the power within a national culture.

Public Health. I. Breslow, Lester. Determinants of Public Health, pp. 2153-57; II. Duffy, John. History of Public Health, pp.2157-61; III. Beauchamp, Dan E. Philosophy of Public Health, pp. 2161-66; IV. Soskolne, Colin. Public-Health Methods: Epidemiology and Biostatistics, pp. 2166-73. In Encyclopedia of Bioethics, revised edition, ed. Warren T. Reich. New York: Simon \& Schuster Macmillan, 1995.

The essays provide a clear and concise background for understanding the development of the public health movement. Beauchamp writes that any philosophy of public health must include a distinct emphasis on community, giving priority to prevention, and defining a common good, while acknowledging individual autonomy at the same time. Each author provides an extensive, relevant bibliography.

\section{PHILOSOPHICAL AND ETHICAL ISSUES}

Callahan, Daniel. Public Health and Personal Responsibility. In his False Hopes: Why America's Quest for Perfect Health Is a Recipe for Disaster, p. 173-207. New York: Simon \& Schuster, 1998.

In weighing the issues surrounding personal accountability for health, Callahan proclaims that “. . . a sustainable medicine will require an effective continuum of programs of public health, health promotion, and disease prevention, a continuum ranging from education at one end of the spectrum, economic and other incentives in the middle, and some frankly coercive policies at the other end. Education alone, or education and exhortation, cannot do the necessary work. Coercive programs will be necessary . . .." He calls for an open debate on the topic.

Calman, Kenneth C. Ethical Issues in Public Health. Leeds, England: Nuffield Institute for Health, University of Leeds, 1993. 8 p.

This presentation to the Nuffield Institute by then Chief Medical Officer Calman focuses on the tension among competing value systems in health services administration. Calman finds that " $[\mathrm{t}] \mathrm{he}$ role of ethics, and the development of an ethical 
framework, is to reduce the uncertainty in decision making;" he refers to the work of Daniel Callahan on the weighing of factors that promote "quality of life," not just "health."

Charlton, Bruce G. Public Health Medicine-A Different Kind of Ethics? Journal of the Royal Society of Medicine 86(4): 194-95, April 1993.

Noting that the physician-patient relationship dates back to prehistory while public health emerged only in the nineteenth century, Charlton argues that the clinical imperative ("something must be done") essential to the clinical encounter must not be adopted by public health. He calls upon public health professionals to resist ". . . the constant temptation for government to be seen to be 'doing something' to tackle illness and disease by making public health interventions despite lacking scientific evidence for efficacy" and to act as "... . bulwark[s] against political pressure towards interference without good cause."

Cole, Philip. The Moral Bases for Public Health Interventions. Epidemiology 6(1): 78-83, January 1995.

Cole describes four major types of preventive public health activities-education, policy advocacy, legislation, and research - and presents and evaluates moral justifications for these programs. He contends that public health laws must be moral, "[i]ntrusive, paid for with public funds, and backed by the police power of the state." Cole reminds of the contract each individual has with the government for life, liberty, pursuit of happiness, autonomy, and privacy.

Coughlin, Steven S., and Beauchamp, Tom L., eds. Ethics and Epidemiology. New York: Oxford University Press, 1996. 312 p.

Epidemiologists, ethicists, and legal scholars discuss theoretical and practical moral problems in epidemiology. Topics included are informed consent, privacy and confidentiality, balancing risks and benefits, the study of vulnerable populations, review boards, and professional education.

Cunningham, George C. A Public Health Perspective on the Control of Predictive Screening for Breast Cancer. Health Matrix: Journal of Law-Medicine 7(1): 31-48, Winter 1997.

Pointing out that screening for breast cancer must be safe and effective with reasonable criteria, Cunningham discusses seven important steps to be analyzed: (1) the problem to be screened should be a significant public problem; (2) the tests must be reliable; (3) a clear diagnostic test should separate true from false positives; (4) there "must be effective intervention to prevent or ameliorate the consequences of the disorder"; (5) resources should be available for counseling and other interventions; (6) the screening would be seen as "worthwhile and practical" for both those screened and health care providers; and (7) screening should be "cost beneficial and cost effective."

Gaughwin, Matt. Post Structuralism and Other 'Species' in Public Health-A 'Darwinian' View. Australian Journal of Public Health 19(4): 430-33, August 1995.

The author uses evolutionary and ecological metaphors to suggest that those who administer public health would benefit looking at the field in new ways, so that minimizing suffering would be the primary objective.

Lake, Lisa Taylor. A Partnership for Public Health. Minnesota Medicine 80(8): 20-24, August 1997.

Lake reports on a conference held in Minnesota in June 1997 to examine "ways clinical medicine and public health can unite to achieve community health goals." Saying that medicine and public health worked together in the nineteenth century to eliminate infectious disease, unsafe water, and unsanitary conditions, Lake notes that speakers at the conference urged the two fields to work together to solve community health problems. The importance of preventive care, particularly in education concerning human behavior, was stressed.

Lupton, Deborah. The Imperative of Health: Public Health and the Regulated Body. London: Sage Publications, 1995. $181 \mathrm{p}$.

Lupton sees health as a "moral imperative," a part of society's norms expressed through public policy. She "combines sociological, anthropological, historical, and cultural studies approaches to analyse the symbolic nature of public health practices" and to look at their meanings. Topics include a history of the public health movement and a discussion of the ways in which health promotion justifies its goals and objectives.

McCormick, James. Medical Hubris and the Public Health: The Ethical Dimension. Journal of Clinical Epidemiology 49(6): 619-21, June 1996.

Stating that the "responsibility for conclusive evidence should apply to the whole field of public health," McCormick says that if a "public health policy is ineffective or harmful, whole populations run the risk of diminished health." He urges a "degree of certainty ... much greater in matters of 
public health than in the conduct of the ordinary [physician] clinical consultation."

Miles, Steven. The Role of Bioethics and Access to US Health Care: Is Bioethics One of Kitty Genovese's Neighbors? Bioethics Examiner 1(2): 1-2, Summer 1997.

Referring to a rabbi's comments that “. . . a medical ethicist [is] a person who gets called to rationalize turning off life support," Miles compares MEDLINE citations for medical ethics articles on futility to citations for access to health care and proclaims that "[o]ur failure to provide universal health insurance ... [ignores] personal autonomy and justice more profoundly than "futility" policies could ever do." He concludes that the ". . . silence of ethicists who profess to watch the health care neighborhood is akin to Kitty Genovese's neighbors who passively listened to her struggles from the safety of their houses while she was dying in the streets."

Morone, James A. Enemies of the People: The Moral Dimension to Public Health. Journal of Health Politics, Policy and Law 22(4): 993-1020, August 1997.

Arguing that moral images and stereotypes have "powerful political consequences," Morone suggests how moral stigmas are constructed and how they are used in public health debates-e.g., alcohol abuse or drug addiction. He thinks that all social policy comes down to a simple division of "us and them ... images of vice and virtue" used to sort out "the moral us from the threatening them." Saying that "[p]ublic health ultimately rests on the search for a shared solution to common troubles," he asks how to construct such a community.

Putting Public Health Back Into Epidemiology. [Editorial.] Lancet 350(9073): 229, 26 July 1997.

The editors say that clinical epidemiology is a "central tool in public health" and urge that studies neither be too narrow-i.e., focusing only upon disease-nor too "wooly." They call "for a conscious effort to restore public health to epidemiology by, for example, reorientating its focus to global issues such as war, poverty, and environmental warming and to the social aspects of health and disease."

Weed, Douglas L., and McKeown, Robert E. Epidemiology and Virtue Ethics. International Journal of Epidemiology 27: 343-50, 1998.

Instead of principle-based ethics, Weed and McKeown examine the ethics of epidemiology in light of virtue, or character ethics, and find that its application is “. . . necessary (although not sufficient) to solve the moral problems facing epidemiologists." Urging introspection to examine both virtues and vices and a strong mentor system, the authors suggest that an emphasis on virtue can "improve the profession and practice of epidemiology."

Weed, Douglas L. Alcohol, Breast Cancer, and Causal Inference: Where Ethics Meets Epidemiology. Contemporary Drug Problems 21(1): 185-204, Spring 1994.

Weed describes how bioethics relates to a consideration of moderate drinking and health. He says that "causal inference methods" utilize "recommendations [that], although based in part on scientific evidence, are not strictly scientific, but rather are value-laden judgments regarding what ought to be done in certain circumstances. They are therefore, moral decisions with considerable empiric input." He goes on to describe principlism and casuistry as two bioethical methods and says "causal inference methodology [in epidemiology] can be described in casuistic terms."

Weed, Douglas L. Underdetermination and Incommensurability In Contemporary Epidemiology. Kennedy Institute of Ethics Journal 7(2): 107-27, June 1997.

Weed reviews the problems inherent in "causal inference"-i.e., using statistical data to determine whether a specific disease results from a certain condition. The author uses the example of two studies of induced abortion and breast cancer that come to different conclusions using the same data. For a comprehensive discussion of the concepts involved, Weed refers to the issue of the Journal of Medicine and Philosophy (20(3), June 1995) that focuses on bioethics and the philosophy of science.

Wikler, Daniel. Presidential Address: Bioethics and Social Responsibility. Bioethics 11(3 \& 4): 185-92, July 1997.

Wikler thinks that there is a new approach to bioethics, that of population health, drawing on a "wider literature of biological and social sciences, along with the humanities and management sciences." The focus will be on health as much as health care and will be global in concept. He discusses the idea of the bioethicist as reformer as well as scholar.

\section{SOCIOECONOMIC AND LEGAL PERSPECTIVES}

Amick, Benjamin C.; Levine, Sol; Tarlov, Alvin R.; and Walsh, Diana Chapman; eds. Society \& Health. New 
York: Oxford University Press, 1995. 374 p.

Contributors look at the ways in which society influences health, with chapters about research on the social environment's contribution to health status through family, community, race, gender, class, the economy, workplace, and culture. The authors write that "[o]ur goal in this volume is to raise social factors and social processes into sharper focus as determinants of health," which they think have both policy and political implications.

Cassileth, Barrie R.; Vlassov, Vasily V.; and Chapman, Christopher C. Health Care, Medical Practice, and Medical Ethics in Russia Today. JAMA, Journal of the American Medical Association 273(20): 1569-73, 24/31 May 1995. [See Pellegrino.]

Holding that the "Soviet leaders withheld internationally accepted standards of medical ethics, human rights, and patient protection," the authors indicate causes for the poor health status of the Russian people, both in the past and in current situations. They discuss access to care, surplus of physicians, and low quality of care, and say that Russia's public health system was a "mirage" created for the outside world. New codes and regulations are beginning to offer ethical health care to the citizens in an effort to provide a better quality of life.

Chavkin, Wendy. Topics for Our Times: Public Health on the Line-Abortion and Beyond. American Journal of Public Health 86(9): 1204-6, September 1996.

Chavkin says that government restrictions impose health risks on women and urges public health professionals to focus on the health of populations. "Data from the United States and around the world consistently demonstrate that when abortion is legal and accessible, both maternal and infant mortality rates decline."

Edgar, Andrew; Salek, Sam; Shickle, Darren; and Cohen, David. The Ethical QALY: Ethical Issues in Healthcare Resource Allocations. Surrey, England: Euromed Communications Ltd., 1998. 168 p.

Funded by the European Commission, the book reports on a research project looking at the allocation of health care resources "by examining the role that quality of life measures could play in allocating those resources." A group of public health physicians, health economists, psychometricians, and philosophers studied the "moral criticism of QALYs" (Quality Adjusted Life Years) and to assess the potential of QALYs. They divide the book into five sections: choices for health care, maximizing health gain, technical criticisms and resolutions, ethical criticisms, and the ethical QALY.

Faden, Ruth R., and Kass, Nancy E., eds. HIV, AIDS, and Childbearing: Public Policy, Private Lives. New York: Oxford University Press, 1996. 492 p.

In the context of HIV/AIDS and reproductive autonomy, this collection contains analytic discussions and reports of empirical research on issues such as informed consent and wrongful birth. Alternative options for both clinical and public health practice are presented.

Gostin, Lawrence O. The Resurgent Tuberculosis Epidemic in the Era of AIDS: Reflections on Public Health, Law, and Society. Maryland Law Review 54(1): 1-131, 1995.

Gostin "examines the biological, social, and behavioral causes of the epidemic, and suggests a comprehensive public health strategy for curtailing tuberculosis and other infectious diseases." $\mathrm{He}$ argues that traditional concepts of public health law "should focus primarily on aggregate harms to communities" and offers strategies "for achieving a population-based objective, and theoretical constructs for thinking about constitutional law and disability law."

Gostin, Lawrence O.; Lazzarini, Zita; Neslund, Verla S.; and Osterhoim, Michael. The Public Health Information Infrastructure: A National Review of the Law on Health Information Privacy. JAMA, Journal of the American Medical Association 275(24): 1921-27, 26 June 1996.

The authors review and analyze the laws in all states, the District of Columbia, and Puerto Rico that "regulate the acquisition, storage, and use of public health data [in order] to offer proposals for reform of the laws on public health information privacy." They urge establishment of an independent data protection commission and justification of the collection of personally identifiable information; in addition, subjects should be informed about data practices, data should be held and used under fair information practices, identifiable health information should have legally binding privacy and security assurances with penalties for any breach, data disclosure should be made only for the original collection purposes, and secondary uses should be allowed only with informed consent.

Grytten, Jostein; Rongen, Gunnar; and Sorensen, Rune. Can a Public Health Care System Achieve Equity? The Norwegian Experience. Medical Care 33(9): 938-51, September 1995.

In a study to look at inequalities in health care 
utilization, the authors think that their government is mistaken in thinking that utilization of health services is independent of patient income, even though fees are low. The authors conclude that people with low incomes are sicker, with a greater need for health care.

Halverson, Paul K.; Mays, Glen P.; Kaluzny, Arnold D.; and Richards, Thomas B. Not-So-Strange Bedfellows: Models of Interaction Between Managed Care Plans and Public Health Agencies. Milbank Quarterly 75(1): 113-38, March 1997.

Saying that public health agencies are becoming active in the field of managed care, the authors examine the interorganizational relations that are being formed. They describe different models of collaboration and the policy implications that ensue, but hold that there is "potential for improving health system performance" in such alliances.

Kilwein, J. H. Medicine As an Agency of Social Control. Part One. Journal of Clinical Pharmacy and Therapeutics 19(5): 275-78, October 1994; Part Two. Journal of Clinical Pharmacy and Therapeutics 19(6): 333-34, December 1994; Part Three. Journal of Clinical Pharmacy and Therapeutics 20(1): 1-3, February 1995; Part Four. Journal of Clinical Pharmacy and Therapeutics 20(2): 49-53, April 1995. Kilwein says that he wrote the four part article to comment on the "increasing pervasiveness in modern society" of medicine's social control role. He illustrates this with such examples as the promotion of exercise, ascetic diet, and sexual abstinence, as well as the promotion of healthy life styles. In the final part, Kilwein discusses past health epidemics or problems falsely linked to specific populations such as immigrants, poor people, different races, or the institutionalized. He thinks that positive health improvements have been made, but that currently the phrase "it's for your own good" is a way for public health to "control the masses," and he concludes that "a society willing to sacrifice significant civil liberties for physical well-being will probably end up with neither."

The Moral Maze of Public Health. [Editorial.] Lancet 349(9052): 583, 1 March 1997.

The editors say that "to ask for public health to be removed from politics would be naive," but state that "political squeamishness over so-called moral concerns has hindered, diverted, or halted numerous sensible public-health initiatives."

Pellegrino, Edmund D. Guarding the Integrity of Medical Ethics: Some Lessons from Soviet Russia.
JAMA, Journal of the American Medical Association 273(20): 1622-23, 24/31 May 1995. [See Cassileth.] Commenting on Cassileth's article about the decline of Russia's public health under the Soviet regime, Pellegrino notes that corruption undermines "any health care system not designed with care of the patient as its primary driving force" and that "medical ethics must maintain independence from political exigency." He writes that assisted suicide legislation and requirements for Illinois physicians to pronounce death by lethal injection are already in effect in the United States, violating "ethical precepts of the health professions" and eroding the "integrity of medical ethics."

Public Health and the Law. I. Grad, Frank P. Philosophy of the Law of Public Health, pp. 2173-78. II. Beauchamp, Dan E. Legal Moralism and Public Health, pp. 2178-81. In Encyclopedia of Bioethics, revised edition, ed. Warren T. Reich. New York: Simon \& Schuster Macmillan, 1995.

The authors provide a broad overview of public health law. Grad divides his essay to cover historical background, expansion of public-health law, major public-health approaches, public health and AIDS, and genetic privacy. Pointing out the "offensive" behavior has driven moralistic public law, he discusses public health and alcohol policy, smoking and public health, and moralism and the AIDS epidemic. With each essay, articles directly related within the encyclopedia are cited as well as pertinent articles from other sources.

Siegel, Michael; Carol, Julia; Jordan, Jerie; Hobart, Robin; Schoenmarklin, Susan; DuMelle, Fran; and Fisher, Peter. Preemption in Tobacco Control: Review of an Emerging Public Health Problem. JAMA, Journal of the American Medical Association 278(10): 858-63, 10 September 1997.

The authors looked at local tobacco control ordinances and say that the tobacco industry "has advanced legislation in 29 states that preempts local authority to regulate tobacco." They conclude that "preventing the enactment of new preemption laws and repealing existing ones should become a public health priority."

Taylor, Carl E. Ethical Issues Influencing Health for All Beyond the Year 2000. Infectious Disease Clinics of North America 9(2): 223-33, June 1995.

Taylor thinks that the slogan "Health for All by the Year 2000" "implies a resistance to anyone from the outside imposing a uniform definition of health on any country; each should allow its own definition of health to evolve but whatever level is achieved should be available 'for all.' This is a 
practical definition of health equity."

Weed, Douglas L. Preventing Scientific Misconduct. American Journal of Public Health 88(1): 125-29, January 1998.

Describing the nature and extent of scientific misconduct, Weed warns that "Congressional oversight could become a reality, public trust could fray, and perhaps most ominous of all, patients could be harmed." He offers a framework for prevention of such misconduct and suggests that the role of ethics be expanded.

Weiss, Lawrence D. Private Medicine and Public Health: Profit, Politics, and Prejudice in the American Health Care Enterprise. Boulder, CO: Westview Press, 1997. 220 p.

Decrying the lack of access to health care in the United States, Weiss thinks that "modern medicine and public health in America are awash in problems and crises," particularly concerning race and racial health status. Providing a brief background to the current health care system, he discusses the roles that physicians, nurses, hospitals, managed care, alternative care, the drug industry, medical services - e.g. laboratories - and the federal government play in the system. He concludes that elimination of the health insurance industry, by adopting a system like the Canadian single-payer health care system, offers the best solution to the crisis in America's health care.

Whiteis, David G. Unhealthy Cities: Corporate Medicine, Community Economic Underdevelopment, and Public Health. International Journal of Health Services 27(2): 227-42, 1997.

The author analyzes the growth in "corporate dominance in U.S. medical care" along with the "withdrawal of resources from public and community-based health," which has resulted in "declining public health conditions in poor and minority urban communities." He proposes that community economic development be an "essential element of public health policy."

\section{INDIVIDUAL VERSUS SOCIETAL RIGHTS}

Booker, Michael J. Compliance, Coercion, and Compassion: Moral Dimensions of the Return of Tuberculosis. Journal of Medical Humanities 17(2): 91-102, Summer 1996.

Booker analyzes the government plan for controlling tuberculosis, looking at the "moral dimensions of mandatory directly observed treatment (DOT) and involuntary quarantine. It is proposed that a moral response to the control of tuberculosis must be one which is sustainable and which can effectively curtail the spread of the disease at a minimal cost to individual rights."

Brazier, Margaret, and Harris, John. Public Health and Private Lives. Medical Law Review 4(2): 171-92, Summer 1996.

The paper "reviews the legal and moral dilemmas posed for society by infectious disease asking how far society should recognize and enforce an obligation not to expose others to infection." Writing in England, the authors observe that "limitations on autonomy imposed by public health laws to control transmission of communicable diseases are justifiable in principle," holding that there is a strong moral responsibility to protect others. The authors would protect citizens from "unjust discrimination" while seeking laws that "strike the proper balance between rights and responsibilities in the context of communicable disease, and which offer all those whose rights are endangered either by violation of their liberty or by a threat to their health, an adequate legal process to protect such rights."

Freedman, Lynn P. Reflections on Emerging Frameworks of Health and Human Rights. Health and Human Rights 1(4): 314-48, 1995.

Freedman suggests that the "analytical tools of public health can be used in conjunction with emerging theories of human rights to craft effective advocacy strategies, focusing particularly on women's reproductive health and reproductive rights."

Gostin, Lawrence O., and Lazzarini, Zita. Human Rights and Public Health in the AIDS Pandemic. New York: Oxford University Press, 1997. 212 p.

Gostin and Lazzarini review the relationship between public health and human rights dating from the United Nations Charter and the Universal Declaration of Human Rights in 1948 to the International Covenant on Economic, Social and Cultural Rights in 1976. The authors state that the "AIDS pandemic presents a major challenge to public health and human rights" and proceed to examine the concepts of autonomy, informed consent, privacy, and discrimination in that context. Based on this analysis, they propose a seven-step process for evaluating the ethical status of public health programs.

Hearst, Alice, and Heffner, Jason. Public Responsibility and Home Tests for HIV. AIDS Policy and Law 11(5): 8-9, 22 March 1996.

Hearst and Heffner urge a compassionate and responsible approach when considering home test kits for HIV/AIDS diagnosis. They note that 
"privacy is a language of both liberty and isolation" and say all should be "wary of the dangers of exalting an individualism that is inattentive to community obligations."

Leavitt, Judith Walzer. Typhoid Mary: Captive to the Public's Health. Boston: Beacon Press, 1996. 331 p. Historian Leavitt looks at Mary Mallon, "Typhoid Mary," to explore the perspectives of public health officials, the law, and the individual. She opines that Mallon's experience raises questions as to how much individual liberty each person must sacrifice to protect the health of the public.

Mann, Jonathan M. Medicine and Public Health, Ethics and Human Rights. Hastings Center Report 27(3): 6-13, May-June 1997.

Mann thinks that world events and experiences, such as the AIDS epidemic and humanitarian emergencies in Bosnia and Rwanda, have caused the relationships between medicine, public health, ethics, and human rights to intermingle. Public health and human rights become "allies pressing the need for an ethics of public health, and revealing the rights-related responsibilities of physicians and other health care workers."

Mann, Jonathan. Human Rights and the New Public Health. Health and Human Rights 1(3): 229-233, 1995. Mann says "that the human rights framework describes the essential preconditions for health better than any conceptual model or analysis thus far proposed from within biomedicine or public health." He thinks that those presently involved in public health will resist such a human rights approach, which is more active, seeking societal root causes for poor health, and offers less "engineered" solutions-i.e., fluoridation of drinking water or auto seat belts.

Rosner, Fred. Involuntary Confinement for Tuberculosis Control: The Jewish View. Mount Sinai Journal of Medicine 63(1): 44-48, January 1996.

Rosner writes that patients with active tuberculosis who are noncompliant with their prescribed medical treatment program pose a serious hazard to themselves and others. Involuntary confinement is ethically justified in secular and Jewish law.

Schmidt, Terri A. When Public Health Competes with Individual Needs. Academic Emergency Medicine 2(3): 217-22, March 1995.

A case of a homeless, alcoholic man with tuberculosis is used to illustrate ethical dilemmas present when society's needs and a patient's actions conflict. The author discusses ethical principles involved and offers two models for ethical decision making in the case.

Stryker, Jeff. Ethical Issues in Public Health Policy Toward HIV Disease. In The AIDS Knowledge Base: A Textbook on HIV Disease from the University of California, San Francisco and the San Francisco General Hospital, 2d ed., ed. P. T. Cohen, Merle A. Sande, and Paul A. Volberding, p. 11.6.1-11.6.4. Boston: Little, Brown and Company, 1994.

Stryker reviews the ethical issues arising from the need for confidentiality in an individual's health status and public health's need for knowledge of $\mathrm{HIV}$-infected persons. He discusses duty to warn, contact tracing, controversies concerning restrictions, and protections inherent in the American with Disabilities Act (ADA).

Unwin, Nigel C. Cycle Helmets - When Is Legislation Justified? Journal of Medical Ethics 22(1): 41-45, February 1996.

Unwin suggests criteria to be met before mandatory cycle helmets are enforced. "The criteria have to do with effectiveness, personal liberty, public acceptability and the promotion of the public health benefits of cycling."

\section{RISK, THE MEDIA, AND PERSONAL CHOICE}

Burris, Scott. Thoughts on the Law and the Public's Health. Journal of Law, Medicine \& Ethics 22(2): 141-47, Summer 1994.

Burris focuses how the choice of one of "two competing visions of health can influence our sense of what role law can play in promoting health." $\mathrm{He}$ describes a view of health wherein "specific ills of the body and access to medical care is the chief determinant of health" and a view in which public "health is an attribute of communities in social and physical environments." $\mathrm{He}$ thinks that an "understanding of health as a characteristic of communities, set in cultural and physical environments, broadens the scope of the debate and the range of measures to promote the public's health."

Dealler, Stephen. Bovine Spongiform Encephalopathy (BSE): The Ethics Concerning Decision about Whether to Continue Taking a Risk with This Disease. Nursing Ethics 3(3): 259-62, 1996. Looking at risk assessment for infected cattle and the possibility of people contracting BSE, Dealler finds the ethics of any action complex. He thinks the Spongiform Encephalopathy Advisory Committee failed to provide helpful advice, and he suggests that risks may have been taken, but that the "absolute level of this risk is currently 
unknown.”

Dugdale, Alan. Hard Sell on Health. [Reply]. Lancet 351(9111): 1292, 25 April, 1998. [See Hard Sell on Health below.]

In response to an editorial calling for more high-powered health promotion campaigns, Dugdale counters that the professional-patient encounter is the arena that needs attention. The author recounts that "[o]ccasionally I get population data on risk levels. Never am I given an assessment of my personal risk and benefit, even by acknowledged experts." He goes on to say that "[a]s public health practitioners, we should continue to disseminate [risk/benefit data] widely and wisely and acknowledge that practices that are risky for some may be safe for others. . . . By combining honesty, humility, and humanity we carers might achieve much more than with the present monopoly of blanket and impersonal advice or commercial-style hard sell."

Foreman, Christopher H., Jr. Plagues' Products \& Politics: Emergent Public Health Hazards and National Policymaking. Washington, DC: The Brookings Institution, 1994. $210 \mathrm{p}$.

Concentrating on hazards that can arise suddenly, Foreman assesses government's roles to investigate, educate, regulate, and conduct research, as well as to fund these activities. $\mathrm{He}$ thinks that policy "tends to be shaped more often by technical and political constraints than by quality or commitment of agency leadership." Foreman argues for improved surveillance as an "essential and politically feasible weapon against emergent public health hazards."

Goldman, Lee. Enlightened Individual Choice vs the Public's Health: Rational Prevention from Whose Perspective? Journal of General Internal Medicine 10(3): 147-50, March 1995.

Goldman offers historical background to questions arising from conflicts in individual interests and public protection, saying that individuals "should be educated to exercise their personal choices in the most effective manner." Discussing problems of cost benefits and capitation and noting that choices can increase costs, he asks if there is a solution. He urges more research to improve understanding of preferences and attitudes among groups and individuals.

Hard Sell for Health. [Editorial.] Lancet 351(9104): 687, 7 March, 1998. [See Dugdale above.]

Noting that there is a "disconnect" between public health campaigns to combat coronary heart disease (CHD) and office visit instruction, the editors call for a change from "cheerless, charmless, and cheap" health promotion ads to ones that ". . . derive from the clinical consultation." They ask "[m]ight not even the most recalcitrant offenders be moved to reconsider their habits by a campaign that reaches out to the individual to tell them that their government cares for their health, and which, to prove it, provides a national network of free and accessible health-advice centres staffed by non-judgmental health professionals."

Hunt, Geoffrey. Some Ethical Ground Rules for BSE and Other Public Health Threats. Nursing Ethics 3(3): 263-67, 1996.

Commenting on the Dealler article (see above), Hunt thinks that action should be taken to ensure that BSE is controlled, and he poses questions to specific professional associations and regulatory bodies in the UK.

Seedhouse, David. Health Promotion: Philosophy, Prejudice and Practice. Chichester, England: John Wiley \& Sons, 1997. 202 p.

Calling health promotion "a magpie profession" composed of expertise from a range of other disciplines, Seedhouse observes that this hodgepodge heritage is obscured by the illusion that all share the same ethics in pursuit of the common good. The author states that health promotion is intrinsically "prejudiced" by the values upon which it is based, but that prejudice can be made a virtue by "acknowledging it and using it to set limits on those health promotion interventions carried out under its aegis."

Snider, Dixie E. Patient Consent for Publication and the Health of the Public. JAMA, Journal of the American Medical Association 278(8): 624-26, 27 August 1997.

Discussing requirements in obtaining informed consent and maintaining privacy, Snider writes that, in particular, public health professionals' patients are the "community, the state, the nation, and the world" and that such professionals are "responsible to society at large," acting "in its best interest." The author raises questions as to how best to implement disclosure requirements agreed upon by medical journal editors.

University of Minnesota, Center for Biomedical Ethics. Sinners, Saints \& Health Care: Individual Responsibility for Health - Ethical, Legal and Economic Questions [Summary Report]. Minneapolis, MN: Center for Biomedical Ethics, December 1994. $13 \mathrm{p}$.

A conference held at the University of Minnesota on 19 May 1994 addressed the issue of 
accountability for disease prevention. Arthur Caplan opened the event by noting that "[a]ll this talk of personal responsibility ... wears its ethics on its sleeve ... [but] in the vast literature of bioethics . . . there's very little discussion of what personal responsibility means ....." Conference sessions addressed such issues as redirecting health promotion activities away from changing individual behavior to affecting mass population trends, and the role the Americans with Disabilities Act plays in illuminating the "blame the victim" attitude prevalent in our culture.

Viscusi, W. Kip. Smoking: Making the Risky Decision. New York: Oxford University Press, 1992. $170 \mathrm{p}$.

Using data on smoking risk-perception from several surveys, Viscusi suggests that the image of smokers as "ignorant of smoking's hazards and incapable of making risky choices in a reliable manner" is a stereotype. The author goes on to discuss risk-perception bias and observes that "... for different classes of smoking risks the amount of information provided increases rather than eliminates the bias in risk assessment."

\section{GENETICS AND PUBLIC HEALTH}

Clayton, Ellen Wright; Steinberg, Karen K.; Khoury, Muin J.; Thomson, Elizabeth; Andrews, Lori; Kahn, Mazy Jo Ellis; Kopelman, Loretta M.; and Weiss, Joan O. Informed Consent for Genetic Research on Stored Tissue Samples. JAMA, Journal of the American Medical Association 274(22): 1786-92, 13 December 1995.

The authors participated in a workshop jointly sponsored by the National Institutes of Health (NIH) and the Centers for Disease Control and Prevention (CDC) in July 1994 to examine the problems involved in collecting tissue samples for genetic research. They make recommendations regarding informed consent and the use of both anonymous and identified samples, and they discuss the implications of their recommendations for public health investigations of disease clusters.

Hiller, Elaine H.; Landenburger, Gretchen; and Natowicz, Marvin R. Public Participation in Medical Policy-Making and the Status of Consumer Autonomy: The Example of Newborn-Screening Programs in the United States. American Journal of Public Health 87(8): 1280-88, August 1997.

The authors surveyed all state-sponsored newborn screening programs and reviewed the newborn screening laws and regulations of each state. They found that only 26 of the states have advisory committees that include consumer representation.
They conclude that quality of services could be improved with "greater public participation in newborn-screening policy-making."

Holtzman, Neil A. Editorial: Genetic Screening and Public Health. American Journal of Public Health 87(8): 1275-77, August 1997.

Holtzman cites various recommendations of the Task Force on Genetic Testing of the National Institutes of Health-Department of Energy Working Group on Ethical, Legal, and Social Implications of Human Genome Research. He thinks that there are "strong arguments for centralized genetic-screening programs under public health auspices. Laboratory quality as well as prompt, consistent, and periodic follow-up of infants with confirmed diagnoses can be ensured."

Jorgenson, Ronald J. Paradigm Shifts and Medical Genetics. [Letter.] American Journal of Medical Genetics 76(1): 99-100, 26 February 1998.

Jorgenson agrees with Khoury (see below), but suggests that geneticists should not only redefine disease, but also "realize that genetics is no different than the rest of medicine and will ultimately be a treatment-oriented subspecialty."

Khoury, Muin J., and the Genetics Working Group, Centers for Disease Control and Prevention. From Genes to Public Health: The Applications of Genetic Technology in Disease Prevention. American Journal of Public Health 86(12): 1717-22, December 1996.

The authors state that "important public health functions are to (1) assess the impact of genes and their interactions with modifiable disease risk factors on the health status of the population; and (2) assess the impact and safety of genetic testing on the population." They urge the public health community to participate in policy development related to the timing and use of genetic testing and to ensure the development of public health genetic programs.

Khoury, Muin J. Relationship Between Medical Genetics and Public Health: Changing the Paradigm of Disease Prevention and the Definition of a Genetic Disease. American Journal of Medical Genetics 71(3): 289-91, 22 August 1997.

“. . . [I]n order for medical genetics and public health to interact successfully, the public health community needs to change the classical disease prevention paradigm [primary, secondary and tertiary prevention models] and the medical genetics community needs to change the definition of and the approach to the label 'genetic disease." Khoury asks "what is prevention in the context of genetic conditions? ... what is a genetic condition 
after all?" and urges strategies that address unique susceptibilities.

Omenn, Gilbert S. Comment: Genetics and Public Health. American Journal of Public Health 86(12): 1701-4, December 1996.

Omenn provides an overview of the role genetic testing plays and will play in public health, saying that the "[k]nowledge of genetics, use of genetic tools, and interpretation of genetic variation in the highly outbred species we know as humans should permeate all fields of public health research, public health practice, and public health education.

Stone, David H., and Stewart, Susie. Screening and the New Genetics: A Public Health Perspective on the Ethical Debate. Journal of Public Health Medicine
18(1): 3-5, March 1996.

The authors think that future efforts to "subject screening programmes to rational evaluation could be undermined" based on the two reasons that genetic screening is conducted: "to reduce the prevalence of the disorder and to inform the reproductive choices of the individuals and couples at risk." They call the second reason a "paradigm shift in the philosophy of screening in that no preventive principle is involved."

This Scope Note was prepared by Martina Darragh, M.L.S., and Pat Milmoe McCarrick M.L.S., Reference Librarians at the National Reference Center for Bioethics Literature. 